\title{
Design and Development of Multi Pin Welding Fixture for Electron Beam Welding
}

\author{
K. Srinivasulu Reddy* \\ School of Mechanical Chemical \& Materials Engineering, MDME Program, Adama Science \& Technology University, Ethiopia
}

Accepted 13 July 2016, Available online 15 July 2016, Vol.6, No.4 (Aug 2016)

\begin{abstract}
In this paper an attempt is made to design and develop multi pin welding fixture for electron beam welding machine. Welding fixtures hold components of a sub assembly for the purpose of welding them together. To join them successfully, each component must be positioned and held firmly in place during the weld process and this must be done, reliably, again and again. The fixture is capable of supporting ten tubes to be welded in one vacuum. The fixture contains a machine block to which bearings are attached. It also contains sun gear and ten planetary gears which are made up of stainless steel and non-magnetic which prevent the deflection of electrons. The fixture is made of aluminum because of its light weight. Whenever the central gear rotates the planetary gears rotate and due to this the shaft in the planetary gear rotates which rotates the tube present in the shaft so that the welding takes place. Tubes are gripped inside the gear with the help of stainless steel grub screws. Likewise, all the tubes are welded accordingly. Indexing during welding is done by main chuck. This multi pin welding fixture helps in increasing production and helps in reducing time required in repeated vacuum cycles.
\end{abstract}

Keywords: Electron beam welding, welding fixture, indexing

\section{Introduction}

Electron beam welding: Electron beam welding (EBW) is a fusion welding process in which a beam of high-velocity electrons is applied to two materials to be joined. The workpieces melt and flow together as the kinetic energy of the electrons is transformed into heat upon impact. EBW is often performed under vacuum conditions to prevent dissipation of the electron beam.

Electron beam generators (electron guns) designed for welding applications can supply beams with power ranging from a few watts up to about one hundred kilowatts. "Micro-welds" of tiny components can be realized, as well as deep welds up to $300 \mathrm{~mm}$ (or even more if needed). Vacuum working chambers of various design may have a volume of only a few liters, but vacuum chambers with the volume of several hundred cubic meters have also been built.

For proper functioning of the electron gun, it is necessary that the beam be perfectly adjusted with respect to the optical axes of the accelerating electrical lens and the magnetic focusing lens. This can be done by applying a magnetic field of some specific radial direction and strength perpendicular to the optical axis before the focusing lens. This is usually realized by a simple correction system consisting of two pairs of

*Corresponding author: K. Srinivasulu Reddy

DOI: dx.doi.org/10.14741/Ijcet/22774106/6.4.2016.19 coils. By adjusting the currents in these coils any required correcting field can be produced.

After passing the focusing lens, the beam can be applied for welding, either directly or after being deflected by a deflection system. This consists of two pairs of coils, one for each $\mathrm{X}$ and $\mathrm{Y}$ direction. These can be used for "static" or "dynamic" deflection.

Static deflection is useful for exact positioning of the beam by welding. Dynamic deflection is realized by supplying the deflection coils with currents which can be controlled by the computer. This opens new possibilities for electron beam applications, like surface hardening or annealing, exact beam positioning, etc

\section{Materials and methods}

Selection of shaft: Shaft is a common and important machine element. It is a rotating member, in general, has a circular cross-section and is used to transmit power. The shaft may be hollow or solid. The shaft is supported on bearings and it rotates a set of gears or pulleys for the purpose of power transmission. The shaft is generally acted upon by bending moment, torsion and axial force. Design of shaft primarily involves in determining stresses at critical point in the shaft that is arising due to a fore mentioned loading. Other two similar forms of a shaft are axle and spindle. Axle is a non-rotating member used for supporting rotating wheels etc. and do not transmit any torque. 
Spindle is simply defined as a short shaft. However, design method remains the same for axle and spindle as that for a shaft.

\section{A. Standard sizes of Shafts}

Typical sizes of solid shaft that are available in the market are,

Up to $25 \mathrm{~mm} 0.5 \mathrm{~mm}$ increments

25 to $50 \mathrm{~mm} 1.0 \mathrm{~mm}$ increments

50 to $100 \mathrm{~mm} 2.0 \mathrm{~mm}$ increments

100 to $200 \mathrm{~mm} 5.0 \mathrm{~mm}$ increments

Materials for the shaft would be required to possess (a) High strength, corrosion resistant (b) Low notch sensitivity, (c) Ability to be heat treated and case hardened to increase wear resistance of journals, and (d) good machinability. Shafts could be made in mild steel, carbon steels or alloy steels such as nickel, nickelchromium or chrome-vanadium steels. Here stainless steel is used because it is non magnetic in nature.

\section{B. Spur Gears}

Spur gears or straight-cut gears are the simplest type of gear. They consist of a cylinder or disk with the teeth projecting radially, and although they are not straightsided in form (they are usually of special form to achieve constant drive ratio, mainly involute), the edge of each tooth is straight and aligned parallel to the axis of rotation. These gears can be meshed together correctly only if they are fitted to parallel shafts. Spur gears used in this design are made up of stainless steel.

\section{Fixtures}

A fixture is a work-holding or support device used in the manufacturing industry. Fixtures are used to securely locate (position in a specific location or orientation) and support the work, ensuring that all parts produced using the fixture will maintain conformity and interchangeability. Using a fixture improves the economy of production by allowing smooth operation and quick transition from part to part, reducing the requirement for skilled labor by simplifying how work pieces are mounted, and increasing conformity across a production run.

\section{Welding Fixtures}

Welding fixtures hold components of a sub assembly for the purpose of welding them together. To join them successfully, each component must be positioned and held firmly in place during the weld process and this must be done, reliably, again and again.

\section{E. Welding Fixture Requirement}

- Materials being joined in the weld process

- Type of part loading / unloading required (automatic vs. manual)
- Final part measurement requirements

- Desired method of production (short run vs. long run)

\section{F. Orbital Welding}

Orbital welding is a specialised area of welding whereby the arc is rotated mechanically through $360^{\circ}$ (180 degrees in double up welding) around a static work piece, an object such as a pipe, in a continuous process.

The main components of every orbital welding system are the power source and controller, the welding head, water cooler and, where required, a wire feed mechanism. There are a large number of factors that can have an influence on the welding result. These aspects include the arc length, magnitude and pulse frequency of the welding current, welding speed, inert shielding gas, parent material, filler material, weld preparation, and thermal conductivity. Ultimately, a high quality weld is achieved through detailed knowledge of how to precisely adjust all these parameters for each individual welding task.

\section{G. Design Constraints}

- The diameter of the fixture should not exceed $220 \mathrm{~mm}$

- The material should be non-magnetic material and should be able to operate in vacuum.

- The material should be electrically conductive.

- Nylon and Teflon are not used because they are not electrically conductive.

- Brass and bronze cannot be used because of the presence of zinc which vaporizes in vacuum.

- Carbon steels and Stainless steels are not used due to its heavy weight.

- Aluminium is used due to its light weight.

\section{H. Welding of Zirconium}

Zirconium is used widely in many industries for process equipment. Major applications include pressure vessels, heat exchangers, piping, tanks, shafts, mixers, and other mechanical equipment. The material often is chosen for its resistance to corrosion from most organic and inorganic acids, salt solutions, strong alkalis, and some molten salts. It is especially suitable in many sulfuric, nitric, hydrochloric, and acetic acid applications. Zirconium is readily welded using practical inert gas fusion welding techniques such as gas tungsten arc welding (GTAW) and plasma arc welding (PAW), as well as specialized processes such as electron beam and laser welding. The material requires extra attention to cleanness and inert gas shielding to protect the weld zone from foreign materials and atmospheric contamination. Cleanness and shielding are the two most critical factors that affect final weld quality. 
Cladding for nuclear reactor fuels consumes about 1\% of zirconium supply.

For this purpose, it is mainly used in the form of zircaloys. The benefits of $\mathrm{Zr}$ alloys is their low neutroncapture cross-section and good resistance to corrosion under normal service conditions. The development of efficient methods for the separation of zirconium from hafnium is required for this application.

\section{Design Specifications}

Chuck diameter $=230 \mathrm{~mm}$

Fixture diameter $=220 \mathrm{~mm}$

Thickness of the housing $=18 \mathrm{~mm}$

Diameter of the tubes to be welded $=6-15 \mathrm{~mm}$. So we considered planetary shaft diameter as $15 \mathrm{~mm}$.The planetary gear we have chosen is MSG-A2 20

Inside Diameter: $18 \mathrm{~mm}$

Outside Diameter: $44 \mathrm{~mm}$

Hub Diameter: $32 \mathrm{~mm}$

Hub Width: $10 \mathrm{~mm}$

Face Width: $20 \mathrm{~mm}$

No of tooth: 20

The central gear chosen is MSG-A2 50

Inside Diameter: $28 \mathrm{~mm}$

Outside Diameter: $104 \mathrm{~mm}$

Hub Diameter: $50 \mathrm{~mm}$

Hub Width: $10 \mathrm{~mm}$

Face Width: $20 \mathrm{~mm}$

No of tooth: 50

Module of central and planetary gear $=2 \mathrm{~mm}$

Bearings for planetary gears:

Bore Diameter: $15 \mathrm{~mm}$

Outside Diameter: $42 \mathrm{~mm}$

Width: $13 \mathrm{~mm}$

Bearings for central gear:

Bore Diameter: $25 \mathrm{~mm}$

Outside Diameter: $42 \mathrm{~mm}$

Width: $9 \mathrm{~mm}$

Pitch circle diameter of planetary gear $=146 \mathrm{~m}$

\section{Part drawing}

Part drawings of main shaft, small shaft, sun gear, planetary gear, housing and corresponding 3D models drawn in ProE software are shown in fig.1 to fig.6.

\section{A. Main Shaft}

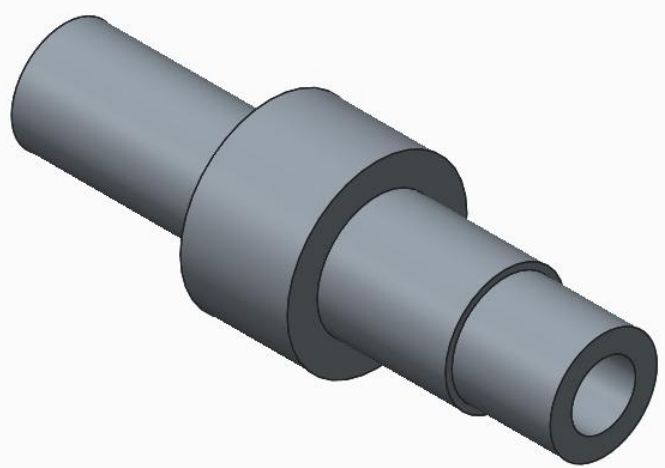

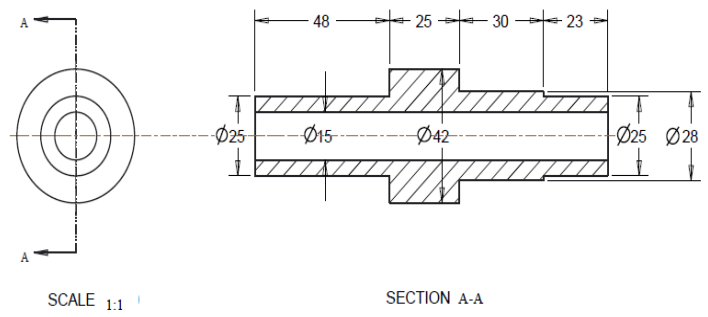

Fig.1 Part drawing and model of Main shaft

B. Small shaft
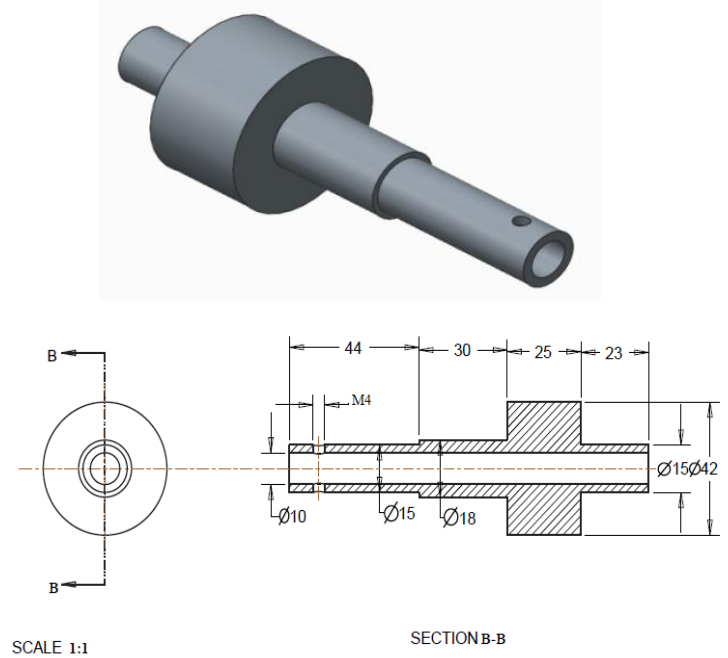

Fig.2 Part drawing and model of small shaft.

\section{Sun gear}

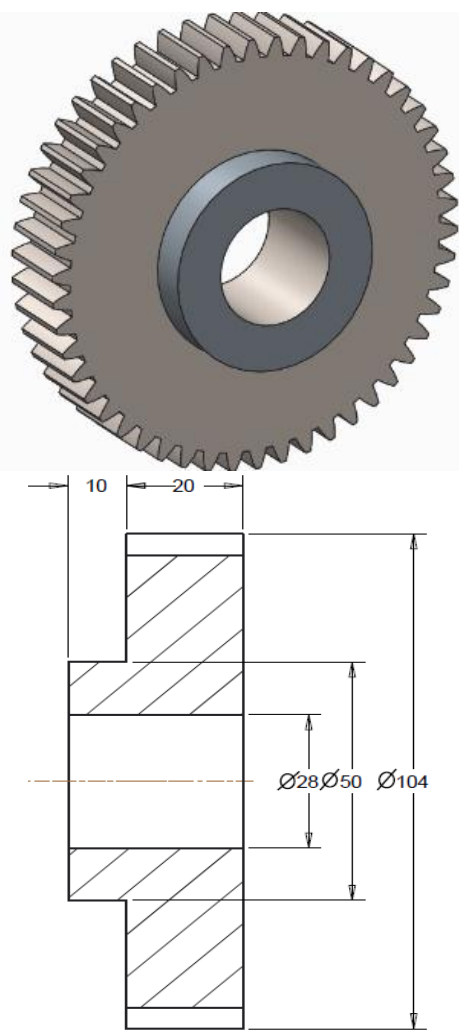

Fig.3 Part drawing and model of sun gear 


\section{Planetary gear}
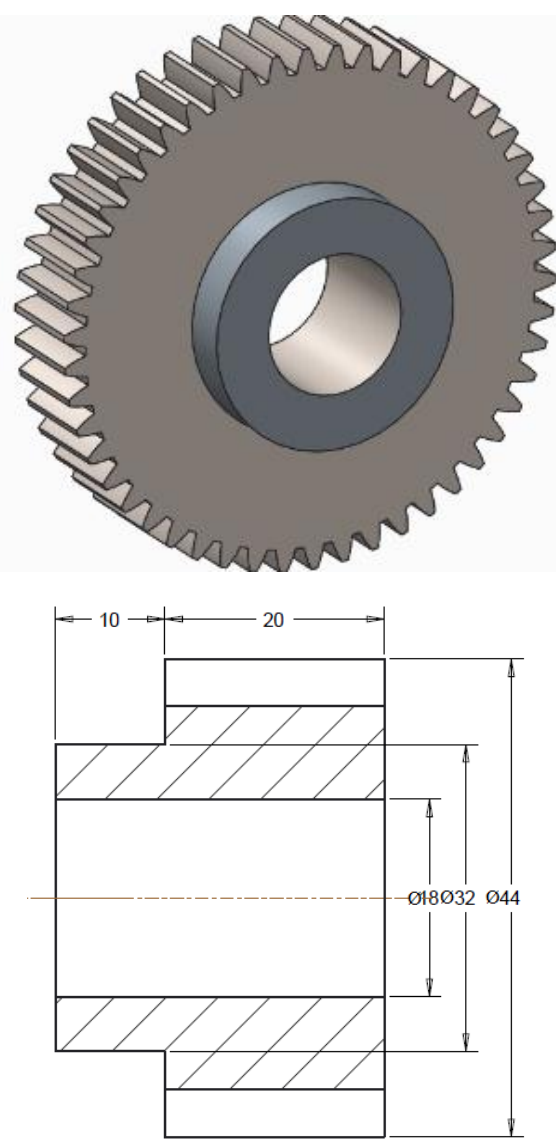

Fig.4 Part drawing and model of planetary gear E. HOUSING
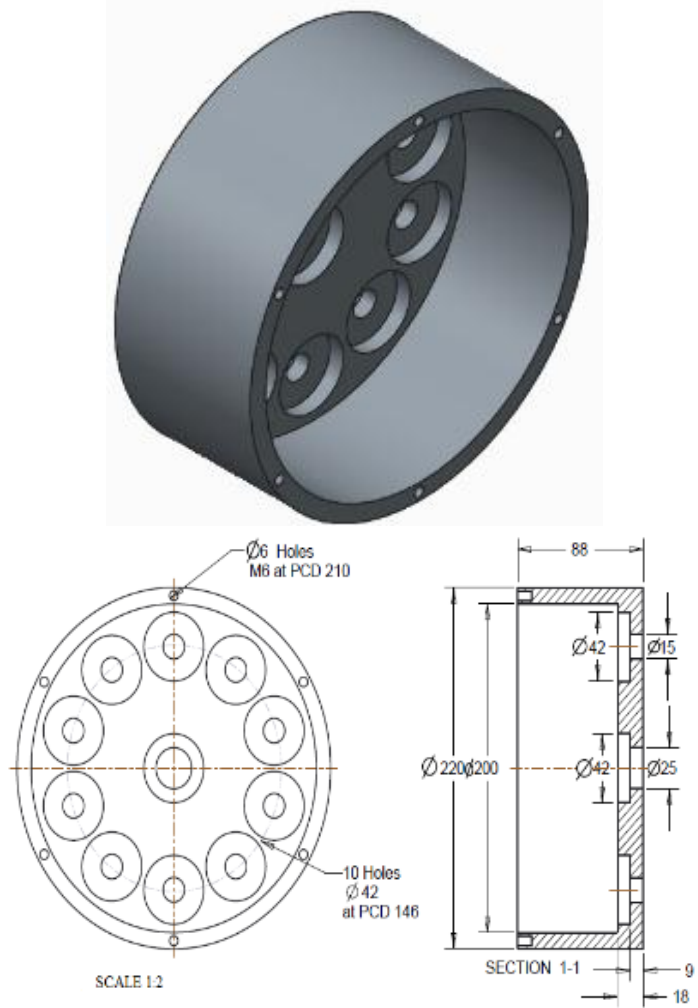

Fig.5 Part drawing and model of housing at section 1-1

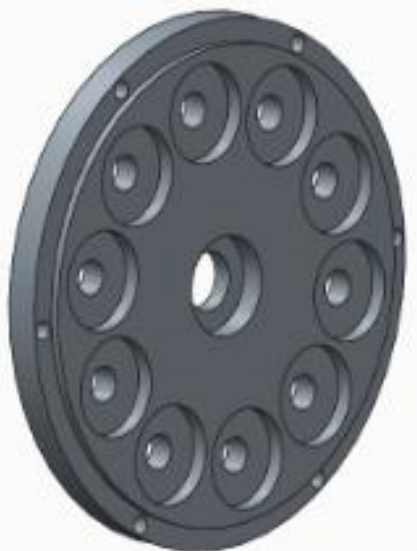

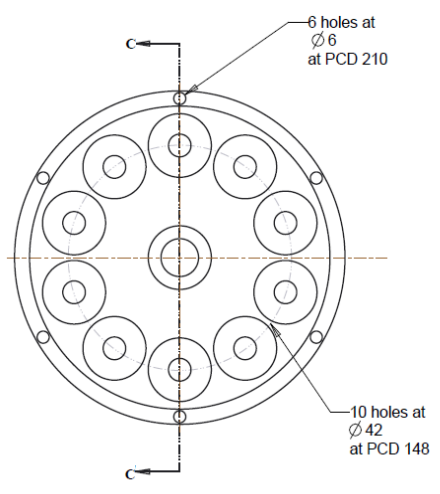

SCALE 1:2

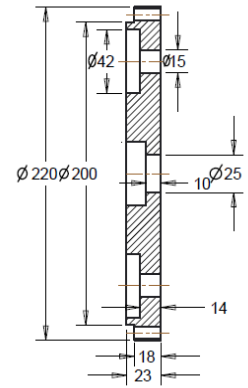

SECTIONC-C
Fig.6 Part drawing and model of other housing at section $\mathrm{C}-\mathrm{C}$

\section{Assembly drawing}

Assembly drawing of the complete fixture and its sectional view is shown in fig.7. Various stages in assembly of the fixture is modelled in ProE software and shown in fig. 8 to fig.13

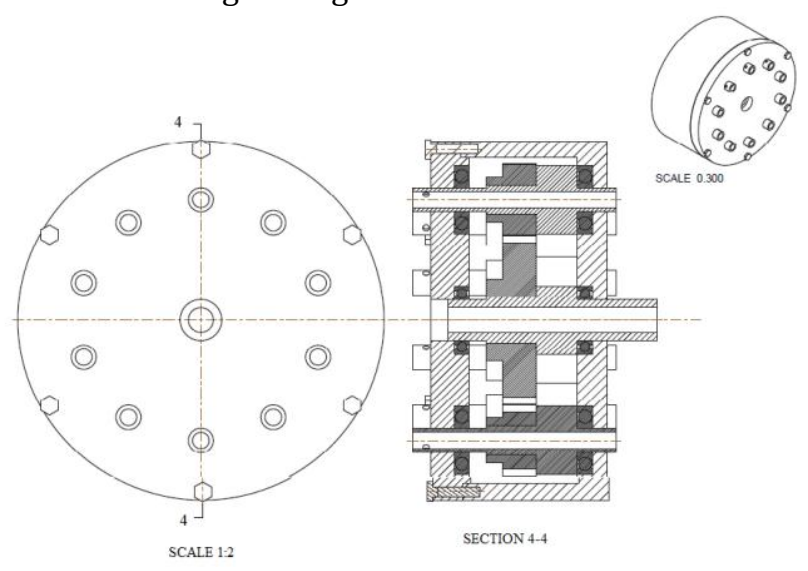

Fig.7 Assembly drawing

A. Assembly fixture using pro/e

A C plate housing of diameter $220 \mathrm{~mm}$ modeled is taken first as shown in fig.5. After assembly main shaft, small shaft, sun gear, planetary gear and bearings, the assembled part is as shown in fig.8. This C plate fixture 
is closed with another plate modeled as shown in fig 6 . Completed assembly of the fixture after closing is shown in fig 9.

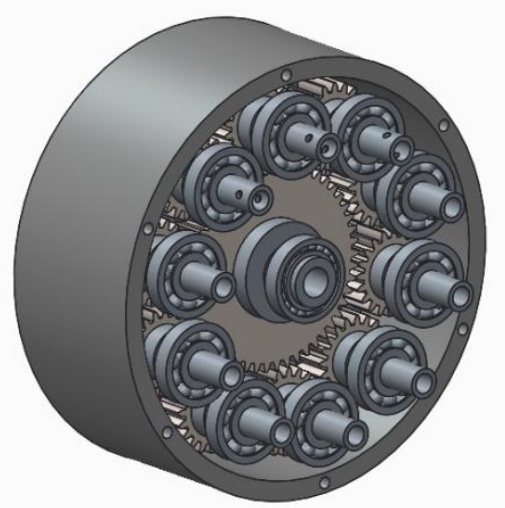

Fig.8 Fixture before closing with plate

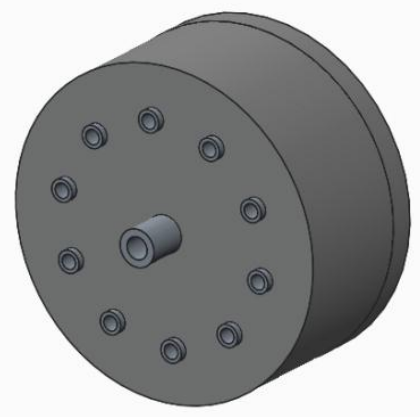

Fig.9 Assembled fixture
To run the main shaft, a dc motor is used with below specifications:

Voltage: 48 Volt DC

Output: 1000 Watt

Sprocket: $11 \mathrm{~T}$ (8mm T8F chain)

Rated speed:3000 RPM

Rated current: $26.7 \mathrm{~A}$

Weight $5.25 \mathrm{Kg}$

\section{Conclusion}

Design and development of multi pin welding fixture for electron beam welding is discussed. The fixture supports ten tubes to be welded in one vacuum. These are the following conclusions:

- This fixture helps in welding of 10 tubes one after the other in one cycle

- The multi pin welding fixture helps in increasing production

- This fixture helps in reducing time required in repeated vacuum cycles.

\section{References}

SKF bearing catalogue www.skf.com/binary/56121486/SKF-rolling-bearings -catalogue

Fundamental of orbital tube welding www.profusiononline.com/welding 